\title{
Development of the Standards of Reporting of Neurological Disorders (STROND) checklist
}

\section{A guideline for the reporting of incidence and prevalence studies in neuroepidemiology}

Derrick A. Bennett, PhD, CStat

Carol Brayne, MD

Valery L. Feigin, MD, $\mathrm{PhD}$

Suzanne Barker-Collo, MA, PhD*

Michael Brainin, MD, FESO, FAHA*

Daniel Davis, MD*

Valentina Gallo, MD,

LSHTM-MSc, PhD*

Nathalie Jetté, MD, MSc, FRCPC*

André Karch, MD, MSc* John F. Kurtzke, MD*

Pablo M. Lavados, MD, $\mathrm{MPH}^{*}$

Giancarlo Logroscino, MD*

Gabriele Nagel, MD, $\mathrm{MPH}^{*}$

Pierre-Marie Preux, MD, $\mathrm{PhD} *$

Peter M. Rothwell, MD, PhD, FRCP*

Lawrence W. Svenson, $\mathrm{BSc}^{*}$

Correspondence to

Dr. Bennett:

derrick.bennett@ctsu.ox.ac.uk

\section{Supplemental data} at Neurology.org

\section{ABSTRACT}

Background: Incidence and prevalence studies of neurologic disorders play an important role in assessing the burden of disease and planning services. However, the assessment of disease estimates is hindered by problems in reporting for such studies. Despite a growth in published reports, existing guidelines relate to analytical rather than descriptive epidemiologic studies. There are also no user-friendly tools (e.g., checklists) available for authors, editors, and peer reviewers to facilitate best practice in reporting of descriptive epidemiologic studies for most neurologic disorders.

Objective: The Standards of Reporting of Neurological Disorders (STROND) is a guideline that consists of recommendations and a checklist to facilitate better reporting of published incidence and prevalence studies of neurologic disorders.

Methods: A review of previously developed guidance was used to produce a list of items required for incidence and prevalence studies in neurology. A 3-round Delphi technique was used to identify the "basic minimum items" important for reporting, as well as some additional "ideal reporting items." An e-consultation process was then used in order to gauge opinion by external neuroepidemiologic experts on the appropriateness of the items included in the checklist.

Findings: Of 38 candidate items, 15 items and accompanying recommendations were developed along with a user-friendly checklist.

Conclusions: The introduction and use of the STROND checklist should lead to more consistent, transparent, and contextualized reporting of descriptive neuroepidemiologic studies resulting in more applicable and comparable findings and ultimately support better health care decisions.

Neurology ${ }^{\circledR}$ 2015;85:821-828

\section{GLOSSARY}

GBD = Global Burden of Disease and Injuries; HIC = high-income countries; LMIC = low- to middle-income countries; PD = Parkinson disease; STROBE = Strengthening the Reporting of Observational Studies in Epidemiology; STROND = Standards of Reporting of Neurological Disorders.

Neurologic diseases are becoming more prevalent as the world's population ages and their burden is expected to increase globally. ${ }^{1}$ These conditions are often subtle in their clinical manifestation and are

prone to misconceptions and misinterpretations. ${ }^{2}$ In epidemiologic studies, neurologic conditions can provide particular challenges including: (1) the diagnostic criteria tend to be variable, or subjective, or prone

Editor's Note: This article was published on June 19, 2015, in the European Journal of Epidemiology and is republished in Neurology with permission. The article was not peer-reviewed by Neurology, and authors' potential conflicts of interest are not disclosed.

*These authors are listed in alphabetical order.

From the Nuffield Department of Population Health (D.A.B.) and Stroke Prevention Research Unit (P.M.R.), University of Oxford; Department of Public Health and Primary Care (C.B.), University of Cambridge, UK; National Institute for Stroke and Applied Neurosciences (V.L.F.), AUT University, Auckland; Department of Psychology (S.B.-C.), University of Auckland, New Zealand; Department for Clinical Medicine and Preventive Medicine (M.B.), Danube-University, Krems, Austria; Faculty of Population Health Sciences (D.D.), University College London; Centre of Primary Care and Public Health (V.G.), Blizard Institute, Queen Mary, University of London, UK; Department of Clinical Neurosciences and Hotchkiss Brain Institute (N.J.), Department of Community Health Sciences and O'Brien Institute for Public Health, University of Calgary, Canada; Research Group Epidemiological and Statistical Methods (A.K.), Helmholtz Centre for Infection Research, Braunschweig, Germany; Georgetown University (J.F.K.), Washington, DC; Vascular Neurology and Stroke Unit (P.M.L.), Neurology Service, Department of Medicine, Clínica Alemana de Santiago, Universidad del Desarrollo and Department of Neurological Sciences, Universidad de Chile, Institute of Neurosurgery, Santiago; Neurodegenerative Diseases Unit (G.L.), Department of Basic Medicine, Neurosciences and Sense Organs, University Aldo Moro, Bari; Department of Clinical Research in Neurology presso Fondazione Card Panico (G.L.), Tricase (LE), University Aldo Moro, Bari, Italy; Institute of Epidemiology and Medical Biometry (G.N.), University of Ulm, Germany; Institute of Tropical Neurology (P.-M.P.), University of Limoges, France; and School of Public Health (L.W.S.), University of Alberta, Edmonton, Canada. Go to Neurology.org for full disclosures. Funding information and disclosures deemed relevant by the authors, if any, are provided at the end of the article. 
to misclassification; (2) the diagnosis of the condition is based on the clinical phenotype but also on data that may require the use of sophisticated technology such as MRI or measuring biomarkers from plasma and CSF; this may require both access to such equipment and specialist skills in order to accurately determine whether an individual is a case (and it is subject to a certain degree of operator-dependent error); (3) there can be considerable heterogeneity in latency periods resulting in variable and long gaps between disease onset and manifestation of symptoms; (4) pathologic confirmation in vivo may be difficult or unavailable for certain neurologic conditions; and (5) many neurologic conditions are rare.

High-quality prevalence and incidence studies of neurologic conditions that follow a systematic approach are essential for estimating the burden of disease globally, for comparison of estimates between various countries and populations, for priority setting, resource allocation, and planning public health approaches. For neurologic conditions, descriptive epidemiologic studies can provide important information on (1) trends and gaps in the health service needs; (2) estimates of morbidity, mortality, and economic burden from these diseases; and (3) can be used for generating new hypotheses on causation or natural history of the disease. Descriptive epidemiologic studies are particularly useful for estimating prevalence, incidence, and morbidity and mortality time trends for studies where global health is of concern. ${ }^{3}$ For instance, there is usually more information available for high-income countries (HIC), but for low- to middle-income countries (LMIC), the number of descriptive epidemiologic studies conducted is sparse. However, studies from both HIC and LMIC can be of poor quality because of poor reporting, poor methodology, or both. ${ }^{4,5}$ It is becoming increasingly important to collect highquality routine information on neurologic disorders from LMIC in addition to those from HIC because these populations are likely to be the ones where the greatest future need for health services and treatment will be required by the middle of this century. ${ }^{6}$

Any approach to attempt to bridge the gap worldwide would require methods or guidelines that reduce inconsistencies in reporting that may identify health disparities between resource-rich and resource-poor regions that are disseminated widely.,8 Good reporting strategies for neuroepidemiologic studies can be used to facilitate meta-analyses and systematic reviews, and are therefore of critical importance. General quality checklists and reporting standards are common for particular types of studies (and, increasingly, expected) in health services research; see, for example, CONSORT for randomized controlled trials, ${ }^{9}$ PRISMA for systematic reviews, ${ }^{10}$ and SQUIRE for quality-improvement studies. ${ }^{11}$ They have 2 main purposes: to help researchers design, undertake, and report robust studies, and to help reviewers and potential users of research outputs assess risk of bias (in terms of validity and reliability). The Strengthening the Reporting of Observational Studies in Epidemiology (STROBE) guidelines $^{12}$ are well known and widely used but were devised for analytical epidemiology (i.e., case-control studies, cohort studies, and cross-sectional studies).

We aim to develop a reporting guideline that outlines the key information to be reported for descriptive health policy research (such as Global Burden of Disease and Injuries [GBD]-type studies), ${ }^{13}$ as studies that are not necessarily obviously population-based, particularly those from settings where there are few data, might be of greater value to projects such as the GBD that need to synthesize evidence, if they were reported better. For example, a systematic review of incidence and prevalence of multiple sclerosis across the Americas found that there were inconsistencies in methodologies and reporting quality among the published studies. ${ }^{14} \mathrm{~A}$ review of dementia in Parkinson disease (PD) found that PD and the prevalence rates of dementia were usually reported in the different age groups, and agespecific prevalence rates of dementia in PD were usually not reported, which made comparisons between studies infeasible. ${ }^{15}$ Another review of the most populous countries found that it was not possible to make a distinction between burden based on the absolute number of cases of PD and burden based on the relative mix of severity of disease as this was poorly reported. ${ }^{16}$ The recent GBD 2013 report on allcause and cause-specific mortality noted that the estimates of Alzheimer disease would be improved by more population-based prevalence studies that use and report standardized definitions and methods. ${ }^{17}$ The primary objective was to develop reporting guidance for incidence and prevalence studies specifically related to neurologic disorders using a consensusbased process, but this information may also be of interest to a general epidemiologic audience.

METHODS We followed the Guidance for Developers of Health Research Reporting Guidelines ${ }^{18}$ and developed a 3-phase consensus process (figure).

Phase I. The process consisted of empirical work, split into 4 different components: (1) a systematic review of reporting guidelines for incidence and prevalence studies in general and reporting guidelines specific to a common neurologic condition (we used stroke as an example for our initial investigations); (2) production of a core set of important items for the reporting of incidence and prevalence studies based on the review of the evidence; (3) assess the quality of reporting of a random sample of published incidence and prevalence studies of the common neurologic condition (stroke); and (4) proposed an initial checklist of a "core set of items" that were then discussed with members of the Standards of Reporting of Neurological Disorders (STROND) 


\section{STROND Collaborative Group assembled (International membership):}

- Neurologists

- Epidemiologists

- Methodologists/Guideline development experts

- Low-income, middle-income and high-income countries

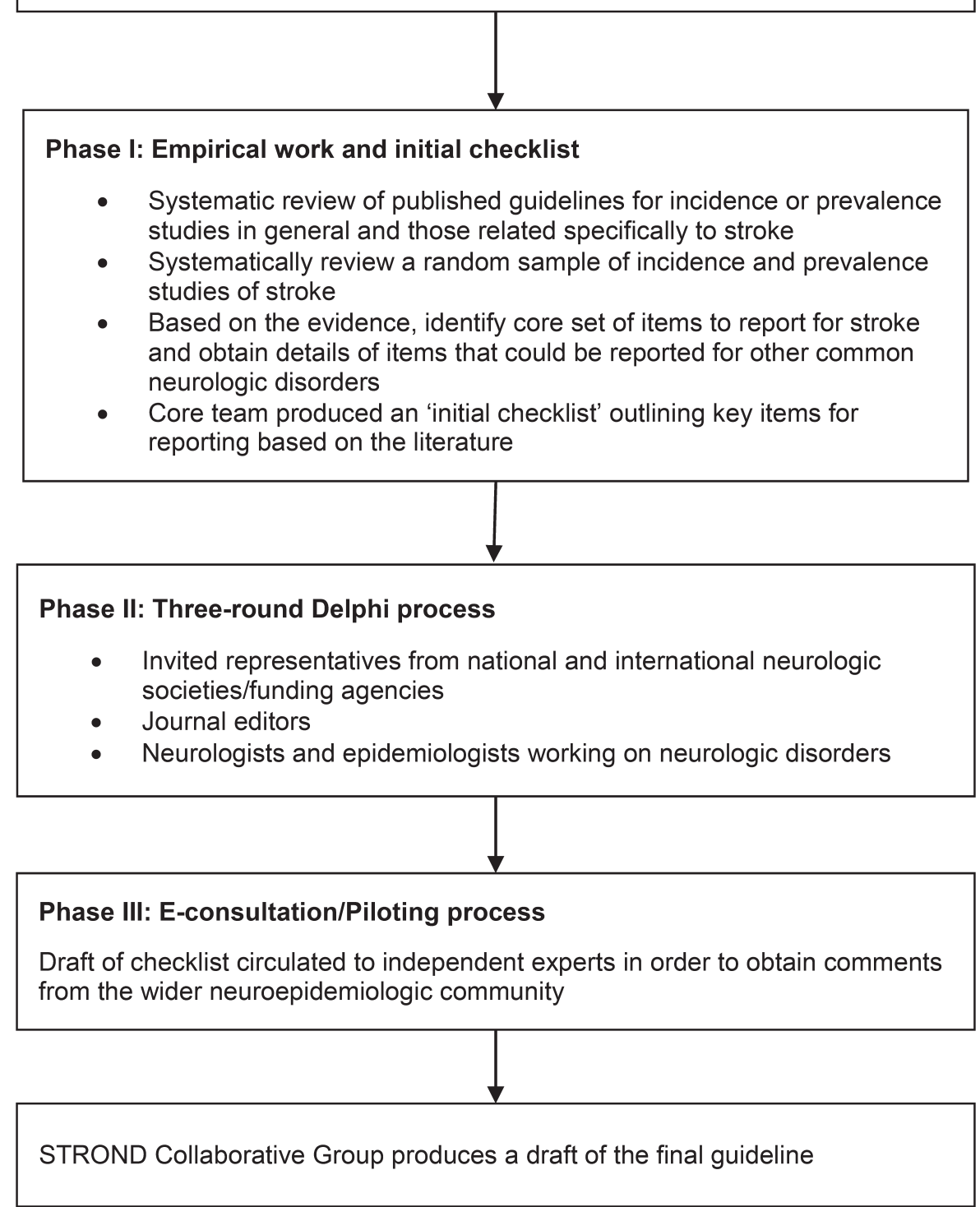

STROND $=$ Standards of Reporting of Neurological Disorders.

collaborative group. Appendix e-1 (on the Neurology ${ }^{\circledR}$ Web site at Neurology.org) summarizes the results of phase I of the development of the STROND guideline.

Phase II. A 3-round Delphi process was conducted using a group of individuals who had expertise in neuroepidemiologic research (who were not members of the STROND group) and agreed to take part in a series of 3 consecutive rounds of questionnaires designed to achieve increasing consensus of opinion on which items should be included in the checklist. ${ }^{19}$ The Delphi process participants were identified by contacting members of neurologic societies via e-mail. An online questionnaire (that included tick boxes and free text comments) was devised based on the relevant version of the questionnaire (and took no more than 15 minutes to complete). This questionnaire was circulated to participants who had agreed to take part in each of the 3 rounds of the Delphi process. Participants remained anonymous, which enabled them to comment freely, but they were required to give their initials and a memorable date when completing the questionnaire for tracking purposes. Respondents were asked to suggest additional items, that they believed were important, that were missing from the initial checklist. After each round, the results were summarized (both quantitative and free text information was summarized) and fed back to the respondents along with the updated version of the checklist that had been revised in the light of the comments received. 
Phase III. Once consensus had been reached on the items to be included in the checklist based on phase I and II findings, then a group of internationally recognized experts on neurologic disorders (as nominated by members of the STROND collaborative group) were contacted as part of a further e-consultation process in order to assess their views (or "pilot") on the contents of the checklist. Once this 3-phase consensus process was completed, a "final checklist" was produced based on the feedback received from all the individuals who had participated.

RESULTS The initial checklist based on a systematic review of the evidence yielded 27 items that were used as part of the first round of the Delphi exercise. Another 11 items that were not included in the initial checklist were included based on feedback from the first round. Table 1 gives details of the background of the participants in the Delphi and the e-consultation processes. Seventy-nine individuals participated in the first round of the Delphi process and described their area of expertise as clinical $(80 \%)$, research $(77 \%)$, policy $(10 \%)$, or methodologic $(20 \%)$ (Delphi process respondents were allowed to check more than one general area of expertise in the online questionnaire). The 79 individuals were from a variety of countries and with contributions from respondents based in high-income $(52 \%)$, middleincome $(30 \%)$, and low-income $(18 \%)$ countries. Of the 79 individuals who completed the first round, 65 individuals took part in the second round $(82 \%)$ and 61 took part in the third and final round $(77 \%)$. Consensus was deemed to be reached when $\geq 70 \%$ of the respondents were in agreement about the utility of a particular checklist item in each successive round of the Delphi process. The e-consultation process invited 30 individuals who were prominent researchers, policymakers, or methodologists in the field of neuroepidemiology. Of the 30 invited individuals, $18(60 \%)$ agreed to participate in the e-consultation/piloting process.

The responses received from the e-consultation/ piloting process were then used to construct the STROND guideline checklist, which is provided in table 2 . The checklist was structured to correspond

\begin{tabular}{|c|c|c|c|c|}
\hline $\begin{array}{l}\text { Gener } \\
\text { respo }\end{array}$ & $\begin{array}{l}\text { area of e } \\
\text { ents }\end{array}$ & of the & hi and $\epsilon$ & sultation process \\
\hline \multirow[b]{2}{*}{$\begin{array}{l}\text { Self-identified area } \\
\text { of expertise }^{a}\end{array}$} & \multicolumn{3}{|c|}{ Delphi process } & \multirow[b]{2}{*}{$\begin{array}{l}\text { e-Consultation/piloting } \\
\text { process }(n=18)\end{array}$} \\
\hline & $\begin{array}{l}\text { Round } 1 \\
(\mathrm{n}=79)\end{array}$ & $\begin{array}{l}\text { Round } 2 \\
(\mathrm{n}=65)\end{array}$ & $\begin{array}{l}\text { Round } 3 \\
(\mathrm{n}=61)\end{array}$ & \\
\hline Clinical & $63(80)$ & $51(80)$ & 50 (82) & $10(55)$ \\
\hline Research & $61(77)$ & $45(70)$ & 44 (72) & $16(89)$ \\
\hline Policy & $8(10)$ & 6 (9) & $7(11)$ & $2(11)$ \\
\hline Methodology & $16(20)$ & $18(28)$ & 15 (24) & 6 (33) \\
\hline
\end{tabular}

Data are $\mathrm{n}(\%)$.

${ }^{\text {a }}$ Respondents were allowed to identify more than one area of expertise. to key components that should be reported in the final manuscript in a similar manner to the STROBE checklist. ${ }^{12}$ The checklist has 15 key items and distinguishes between items that are deemed to be "basic minimum reporting" requirements (items in nonitalic font), and items that are deemed to be "ideal reporting" requirements (items in italic font). For example, the item on the source population (item 6) used in the study has 3 basic minimum reporting requirements: using several different sources for case identification; the core data used to identify individuals (e.g., medical records, administrative databases); and a description of dropouts or exclusions from the source population. The ideal reporting requirements would also have details on the rate of admission for the neurologic condition in the population, details of the health care system in the country where the study was conducted, and details of filters on how the person with the neurologic condition is referred. The checklist also distinguishes between items that relate specifically to incidence or prevalence studies of neurologic disorders.

DISCUSSION We envisage that the STROND checklist will only be used to assess the reporting of prevalence and incidence studies of neurologic disorders. Although this checklist is aimed at reporting of descriptive epidemiologic studies of neurologic disorders, we believe that it would also be of interest to researchers wishing to report their descriptive epidemiologic studies of nonneurologic disorders. The 15-item checklist provides a framework to satisfy the need for completeness and transparency of reporting of incidence and prevalence studies of neurologic disorders. We attempted to strike a balance between adequate detail and concise reporting so we incorporate both "basic minimum reporting" standards as well as "ideal reporting" criteria in the checklist. There is substantial evidence that reporting guidelines improve the completeness of published reports based on natural experiments. ${ }^{20,21}$ As has been done with other reporting guidelines, ${ }^{22}$ we aim to develop a more detailed explanation and elaboration report that provides more detail on the rationale for each item included in the checklist and provides some empirical evidence of good reporting of incidence and prevalence studies for neurologic disorders. The preliminary aims and objectives of the guideline have been posted on the EQUATOR (Enhancing the Quality and Transparency of Health Research) Network ${ }^{23,24}$ and we plan to post the checklist and the explanation and elaboration report on the EQUATOR Web site (http://www.equator-network.org).

The limitations of this project are that the STROND reporting guideline was developed using 
Table 2 Standards of Reporting of Neurological Disorders (STROND): A guideline for the reporting of incidence and prevalence studies in neuroepidemiology

\begin{tabular}{|c|c|c|}
\hline Section/topic & No. & Recommendation \\
\hline \multicolumn{3}{|l|}{ Title \& abstract } \\
\hline Title and abstract & 1 & $\begin{array}{l}\text { (a) Give the type of study design employed using a widely recognized } \\
\text { term in the title or abstract }\end{array}$ \\
\hline & & $\begin{array}{l}\text { (b) The abstract should give an accurate summary of how the study was } \\
\text { conducted and the main findings }\end{array}$ \\
\hline
\end{tabular}

Introduction

Background

Aims and objectives

Methods

Study design

4

Setting

Source population

Participants

Ethical approval

\begin{abstract}
conducted and the main findings
\end{abstract}
Details of the scientific rationale for the study should be reported

State the specific aims and objectives of the study

Give a full description of the study design

Give details of any study protocol (published or unpublished that gives additional useful information on the study design)

If a pilot study has been conducted to inform the main study design, then the findings should be referenced

Clearly defined (usually, but not always, on a geographic basis), and stable, with reliable information on in- and out-migration

Description of how all eligible members of the population were identified and through what data sources (e.g., hospitals, outpatient clinics, death certificates)

Source of data used for the study (e.g., administrative database, medical records). If administrative database used, algorithms for dato extraction should be described

Description of the rate of hospital admission (if applicable) for the neurologic condition in the population

Details of health care system in the country (study region) where the study was conducted (e.g., public vs private health care system)

Description of how a person with the neurologic condition is referred (with the filters) in the country (study region) where the study was conducted

Description and characteristics of response rate/dropouts and exclusion rate if applicable

Definition of cases is clearly identified and presented in sufficient detai

Details of the sampling method are described (are participants representative of the source population?)

Fully validated source of diagnosis or "reference-standard" criteria applied

Definition and justification of the disease severity (preferably using a standardized severity scale) or staging of the disease

Description of how types/subtypes of the neurologic disorder of interest are distinguished (if relevant)

Description of how completeness of case ascertainment was assessed

Description of whether completeness of case ascertainment was adequate

Details of ethics approval/informed consent/data governance should be reported

Incidence studies

Give details of how incidence was determined (based on timing of data collection either prospectively or retrospectively)

Definition and justification of timing of measurements

The data presented to some specified time period (usually whole years or person-time)

Raw numbers are reported in sufficient detail to calculate the appropriate rates (e.g., by age or sex)

Prevalence studies

Give details of specific time points over which estimates are derived (usually defined as the number of cases existing in a specific time point) 
Table 2 Continued

\begin{tabular}{|c|c|c|}
\hline \multirow[t]{6}{*}{ Section/topic } & No. & Recommendation \\
\hline & & $\begin{array}{l}\text { The data presented to some specified time period (usually whole } \\
\text { years) }\end{array}$ \\
\hline & & $\begin{array}{l}\text { Raw numbers are reported in sufficient detail to calculate the } \\
\text { appropriate rates (e.g., by age or sex) }\end{array}$ \\
\hline & 9c & $\begin{array}{l}\text { If disease burden is to be assessed, the study should report details of } \\
\text { burden due to a variety of sources (e.g., disability, disability-adjusted } \\
\text { life years, symptoms, financial, caregiver) }\end{array}$ \\
\hline & $9 d$ & $\begin{array}{l}\text { Report any arrangements for quality checks/data verification/ } \\
\text { triangulation }\end{array}$ \\
\hline & $9 e$ & $\begin{array}{l}\text { Report details of the training of the person administering the } \\
\text { instruments }\end{array}$ \\
\hline \multirow[t]{6}{*}{ Statistical methods } & 10 & $\begin{array}{l}\text { If rates have been standardized (e.g., by age or sex), then the details of } \\
\text { the standard population used should be given }\end{array}$ \\
\hline & $10 a$ & $\begin{array}{l}\text { If possible, } 2 \text { standard populations should be used, one with local } \\
\text { relevance and the other to facilitate international comparisons }\end{array}$ \\
\hline & $10 b$ & $\begin{array}{l}\text { Description of any assumptions made in the calculations should be } \\
\text { reported }\end{array}$ \\
\hline & $10 c$ & An explanation of how missing data were addressed in the analyses \\
\hline & $10 d$ & $\begin{array}{l}\text { Provide a priori estimates of sample size/power assessment/precision } \\
\text { of estimates assessment }\end{array}$ \\
\hline & $10 e$ & Description of any sensitivity analyses \\
\hline \multicolumn{3}{|l|}{ Results } \\
\hline \multirow[t]{3}{*}{ Main findings } & 11 & $\begin{array}{l}\text { Consider a flow diagram that describes how participants were included } \\
\text { in the study (useful in order to assess how a person with the neurologic } \\
\text { condition of interest is referred [with the filters]) }\end{array}$ \\
\hline & $11 a$ & Give appropriate rates with their associated $95 \%$ confidence intervals \\
\hline & $11 b$ & Report results of any sensitivity analyses \\
\hline \multicolumn{3}{|l|}{ Discussion } \\
\hline Key findings & 12 & Summarize the key findings in relation to the study aims and objectives \\
\hline \multirow[t]{2}{*}{ Limitations } & 13 & Discuss potential limitations of the study \\
\hline & $13 a$ & $\begin{array}{l}\text { Include details of risk of bias (e.g., selection bias), completeness of case } \\
\text { ascertainment, and data quality (assessment of its probability, size, } \\
\text { and potential importance) }\end{array}$ \\
\hline \multirow[t]{2}{*}{ Interpretation } & 14 & $\begin{array}{l}\text { Interpret the results in the context of the evidence from other well- } \\
\text { performed studies with similar designs and objectives }\end{array}$ \\
\hline & $14 a$ & $\begin{array}{l}\text { Reliability of the estimates (i.e., based on the reporting of the statistical } \\
\text { methodology, and study design, measurement of key information) }\end{array}$ \\
\hline \multirow[t]{2}{*}{ Generalizability } & 15 & Discuss the external validity of the study findings \\
\hline & $15 a$ & $\begin{array}{l}\text { Are the results consistent with meta-analyses of descriptive } \\
\text { epidemiologic studies on the same topic that cover different settings (if } \\
\text { applicable)? }\end{array}$ \\
\hline
\end{tabular}

a consensus process and thus may only represent the opinions of the participants. However, consensus was reached on both the "basic minimum reporting" standards and the "ideal reporting standards" with $>70 \%$ of respondents in agreement on the items included in successive rounds of the Delphi exercise. Furthermore, the independent group of experts who participated in the e-consultation were all in broad agreement about the items included. In addition, the Delphi technique has been used widely in medical research as a survey method to gain consensus among a group of respondents. ${ }^{25}$ For example, a Delphi exercise process was employed by the Consolidated Standards of Reporting Trials
(CONSORT) investigators when developing this widely used reporting guideline. ${ }^{22}$

Large-scale projects like the GBD Study ${ }^{26}$ need to utilize prevalence and incidence studies that use consistent methods and terminology and also require high-quality reporting in order to provide the required information for their disease-modeling algorithms to adequately estimate disease burden due to these disorders. It is well known that rigorous population-based studies from LMIC are sparse for neurologic disorders (even for stroke), and the quality of reporting in LMIC as well as HIC is in need of improving. ${ }^{13}$ We will aim to translate the checklist into languages other than English as required as well 
as aiming to conduct and support research that investigates the impact of the guidelines on the reporting quality of incidence and prevalence studies in neurologic disorders. ${ }^{7}$ We hope that the introduction and use of the STROND checklist will lead to more consistent, transparent, and contextualized reporting of population-based prevalence and incidence studies of neurologic disorders and that these more applicable findings will lead ultimately to better health care decisions.

\section{APPENDIX}

Core Standard of Reporting of Neurological Disorders (STROND) development team. Dr. Derrick Bennett (Nuffield Department of Population Health, University of Oxford, UK); Professor Carol Brayne (Department of Public Health and Primary Care, University of Cambridge, UK); Professor Valery Feigin (National Institute for Stroke and Applied Neurosciences, AUT University, Auckland, New Zealand); Helen McDonald (National Institute for Stroke and Applied Neurosciences, AUT University, Auckland, New Zealand).

Standard of Reporting of Neurological Disorders (STROND) collaborators. Professor Michael Brainin (Department for Clinical Medicine and Preventive Medicine, Danube-University Krems, Austria); Professor Pierre-Marie Preux (Institute of Tropical Neurology, University of Limoges, France); Professor Peter Rothwell (Stroke Prevention Unit, University of Oxford, UK); Dr. Pablo M. Lavados (Vascular Neurology and Stroke Unit, Neurology Service, Department of Medicine, Clínica Alemana de Santiago, Universidad del Desarrollo and Department of Neurological Sciences, Universidad de Chile, Institute of Neurosurgery, Santiago, Chile); Emeritus Professor John F. Kurtzke (Georgetown University USA); Dr. Suzanne Barker-Collo (Department of Psychology, University of Auckland, New Zealand); Dr. Daniel Davis (Faculty of Population Health Sciences, University College London, UK); Dr. Valentina Gallo (Centre of Primary Care and Public Health, Blizard Institute, Queen Mary, University of London, UK); Dr. Nathalie Jetté (Department of Clinical Neurosciences and Hotchkiss Brain Institute, Department of Community Health Sciences and O'Brien Institute for Public Health, University of Calgary, Canada) André Karch (Research Group Epidemiology and Statistical Methods, Helmholtz Centre for Infection Research); Lawrence W. Svenson (School of Public Health, University of Alberta, Canada); Professor Giancarlo Logroscino (Neurodegenerative Diseases Unit, Departmen of Basic Medicine, Neurosciences and Sense Organs, and Department of Clinical Research in Neurology presso Fondazione Card Panico, Tricase, University Aldo Moro, Bari, Italy); Gabriele Nagel (Institute of Epidemiology and Medical Biometry, University of Ulm, Germany).

Received June 6, 2015. Accepted in final form June 10, 2015

\section{REFERENCES}

1. Whiteford HA, Ferrari AJ, Degenhardt L, Feigin V, Vos T. The global burden of mental, neurological and substance use disorders: an analysis from the Global Burden of Disease Study 2010. PLoS One 2015;10: e0116820.

2. Rao D, Choi S, Victorson D, et al. Measuring stigma across neurological conditions: the development of the Stigma Scale for Chronic Illness (SSCI). Qual Life Res 2009;18:585-595.

3. Murray CJ, Ezzati M, Flaxman AD, et al. GBD 2010: a multi-investigator collaboration for global comparative descriptive epidemiology. Lancet 2013;380:2055-2058.

4. Hirtz D, Thurman DJ, Gwinn-Hardy K, Mohamed M, Chaudhuri AR, Zalutsky R. How common are the "common” neurologic disorders? Neurology 2007;68:326-337.
5. Albert SM. Projecting neurologic disease burden: difficult but critical. Neurology 2007;68:322-323.

6. Vos T, Flaxman AD, Naghavi M, et al. Years lived with disability (YLDs) for 1160 sequelae of 289 diseases and injuries 1990-2010: a systematic analysis for the Global Burden of Disease Study 2010. Lancet 2013;380: 2163-2196.

7. Simera I, Moher D, Hirst A, Hoey J, Schulz KF, Altman DG. Transparent and accurate reporting increases reliability, utility, and impact of your research: reporting guidelines and the EQUATOR Network. BMC Med 2010;8:24.

8. Feigin V, Kurtzke JF, Korczyn A, Beghi E, Brown A. Bridging the gap between experimental and nonexperimental neuroepidemiology, and ultimatelybetween neuroepidemiological research and practice: round table discussion at the First International Congress on Clinical Neurology and Epidemiology. Neuroepidemiology 2009;33:296-304.

9. Schulz KF, Altman DG, Moher D. CONSORT 2010 statement: updated guidelines for reporting parallel group randomised trials. J Pharmacol Pharmacother 2010;1: $100-107$

10. Liberati A, Altman DG, Tetzlaff J, et al. The PRISMA statement for reporting systematic reviews and metaanalyses of studies that evaluate healthcare interventions: explanation and elaboration. BMJ 2009;339:b2700.

11. Oermann MH. SQUIRE Guidelines for reporting improvement studies in healthcare: implications for nursing publications. J Nurs Care Qual 2009;24:91-95.

12. von Elm E, Altman DG, Egger M, Pocock SJ, Gotzsche PC, Vandenbroucke JP. Strengthening the Reporting of Observational Studies in Epidemiology (STROBE) statement: guidelines for reporting observational studies. BMJ 2007;335:806-808.

13. Chin JH, Vora N. The global burden of neurologic diseases. Neurology 2014;83:349-351.

14. Evans C, Beland SG, Kulaga S, et al. Incidence and prevalence of multiple sclerosis in the Americas: a systematic review. Neuroepidemiology 2013;40:195-210.

15. Aarsland D, Zaccai J, Brayne C. A systematic review of prevalence studies of dementia in Parkinson's disease. Mov Disord 2005;20:1255-1263.

16. Dorsey ER, Constantinescu R, Thompson JP, et al. Projected number of people with Parkinson disease in the most populous nations, 2005 through 2030. Neurology 2007;68:384-386.

17. GBD 2013 Collaborators. Global, regional, and national age-sex specific all-cause and cause-specific mortality for 240 causes of death, 1990-2013: a systematic analysis for the Global Burden of Disease Study 2013. Lancet 2015;385:117-171

18. Moher D, Schulz KF, Simera I, Altman DG. Guidance for developers of health research reporting guidelines. PLoS Med 2010;7:e1000217.

19. Steurer J. The Delphi method: an efficient procedure to generate knowledge. Skeletal Radiol 2011;40:959-961.

20. Hopewell S, Ravaud P, Baron G, Boutron I. Effect of editors' implementation of CONSORT guidelines on the reporting of abstracts in high impact medical journals: interrupted time series analysis. BMJ 2012;344:e4178.

21. Turner L, Shamseer L, Altman D, Schulz K, Moher D. Does use of the CONSORT statement impact the completeness of reporting of randomised controlled trials 
published in medical journals? A Cochrane review. Syst Rev 2012;1:60.

22. Moher D, Hopewell S, Schulz KF, et al. CONSORT 2010 explanation and elaboration: updated guidelines for reporting parallel group randomised trials. BMJ 2010;340:c869.

23. Altman DG, Simera I, Hoey J, Moher D, Schulz K. EQUATOR: reporting guidelines for health research. Lancet 2008;371:1149-1150.
24. Simera I, Moher D, Hoey J, Schulz KF, Altman DG. The EQUATOR Network and reporting guidelines: helping to achieve high standards in reporting health research studies. Maturitas 2009;63:4-6.

25. Cialkowska M, Adamowski T, Piotrowski P, Kiejna A. What is the Delphi method? Strengths and shortcomings [in Polish]. Psychiatr Pol 2008;42:5-15.

26. Murray CJ, Ezzati M, Flaxman AD, et al. GBD 2010: design, definitions, and metrics. Lancet 2013;380:2063-2066. 


\section{Neurology}

\section{Development of the Standards of Reporting of Neurological Disorders (STROND) checklist: A guideline for the reporting of incidence and prevalence studies in neuroepidemiology \\ Derrick A. Bennett, Carol Brayne, Valery L. Feigin, et al.}

Neurology 2015;85;821-828 Published Online before print July 10, 2015

DOI 10.1212/WNL.0000000000001866

\section{This information is current as of July 10, 2015}

\section{Updated Information \& Services}

Supplementary Material

\section{References}

Subspecialty Collections

\section{Permissions \& Licensing}

Reprints including high resolution figures, can be found at: http://www.neurology.org/content/85/9/821.full.html

Supplementary material can be found at: http://www.neurology.org/content/suppl/2015/07/10/WNL.0000000000 001866.DC1.html

This article cites 26 articles, 8 of which you can access for free at: http://www.neurology.org/content/85/9/821.full.html\#\#ref-list-1

This article, along with others on similar topics, appears in the following collection(s):

\section{All Clinical Neurology}

http://www.neurology.org//cgi/collection/all_clinical_neurology Incidence studies

http://www.neurology.org//cgi/collection/incidence_studies Other Education

http://www.neurology.org//cgi/collection/other_education Prevalence studies

http://www.neurology.org//cgi/collection/prevalence_studies

Information about reproducing this article in parts (figures,tables) or in its entirety can be found online at:

http://www.neurology.org/misc/about.xhtml\#permissions

Information about ordering reprints can be found online: http://www.neurology.org/misc/addir.xhtml\#reprintsus

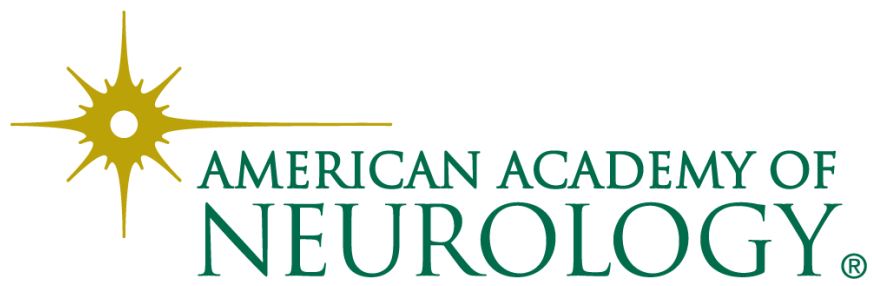

